\title{
Sustainable Transportation System Design
}

\author{
Melis Çolak, İrem Yaprak Utku, Deniz Özmisir, Alican Boz, \\ Tayfun Aydoğdu, Mert Cem Didiş and Emre Nadar
}

\begin{abstract}
As reducing the carbon footprint became one of the topmost concerns of the firms, Company X Turkey has a goal of transforming all of its operations in environmentally sustainable manner. Therefore, they specified their main goal as reducing yearly carbon emission levels of the company by five percent calculated in key performance indicator. Although there are several causes of increased levels of carbon emission, since the control capability of the company is limited in other fields, this study focuses specifically on developing a strategy for reducing the carbon emission generated due to Company X's transportation system in Turkey. The aim of this study is to create a well-designed transportation network through the detection of $\mathrm{CO}_{2}$ emission causes. To lower route-based emission levels, more utilized use of cross-dock locations and alternative fuel usage is recommended, while routing is
\end{abstract}

\section{M. Çolak (凶)}

M.Sc. Industrial Engineering, Baskent University, Ankara, Turkey

e-mail:meliscolak95@gmail.com

\section{İ. Y. Utku}

Garanti Bank, Istanbul, Turkey

e-mail: iyaprak.utku@gmail.com

D. Özmisir

M.Sc. Management, Kuhne Logistics University, Hamburg, Germany

e-mail: denizozmisir@gmail.com

\author{
A. Boz \\ Department of Risk Management Levent, Akbank, Istanbul, Turkey \\ e-mail: alicanboz.26@gmail.com \\ T. Aydoğdu \\ Philip Morris International, Ankara, Turkey \\ e-mail: tayfunaydogdu61@gmail.com
}

M. C. Didiş

Unilever, Umraniye, Istanbul, Turkey

e-mail: Mert.Didis@unilever.com

E. Nadar

Department of Industrial Engineering, Bilkent University, Ankara, Turkey

e-mail: emre.nadar@bilkent.edu.tr 
provided by integer programming. Improvement suggestions including fleet aerodynamics, tire pressure, optimal speed, and acceleration for fleets are constructed in a separate branch to decrease fleet-based carbon emissions in the system.

Keywords Sustainable transportation $\cdot \mathrm{LRP} \cdot \mathrm{CNG} \cdot$ Fleet improvements

\section{Introduction}

"Carbon footprint stands for a certain amount of gaseous emissions that are relevant to climate change and associated with human production or consumption activities." As well as other greenhouse gasses (GHGs), it is known that carbon dioxide $\left(\mathrm{CO}_{2}\right)$ emissions have a major contribution $81 \%$ to climate change in a global manner. Therefore, responsibilities on decreasing the amount of carbon dioxide emissions are shared among all nations around the world, and they try to shift toward a carbonneutral model in each industry in their nation by trying new methodologies and making changes in their policies.

When analyzing carbon footprint of companies, it is important to differentiate between different sources of direct emissions and indirect emissions. Since people are able to choose their travel destination and their travel method, people's travels cause direct emissions. On the other hand, indirect emissions are generated while transferring products between nodes. Since the customer has no control over the distance between the factory and store, the company is held responsible for reducing emissions. Although there are several factors that contribute to $\mathrm{CO}_{2}$ emissions in the transportation system, $72 \%$ of the carbon dioxide emissions are because of road transportation.

The root causes for $\mathrm{CO}_{2}$ emissions can be classified into four main headlines as follows: Route-based problems as decisions like which trucks to use in which networks and optimal route selections, physical and mechanical truck-based problems, fuel-based problems, and speed/traffic-based problems. There are various applications of carbon-free transportation in public transportation in metropolises, in logistic departments of several shipment companies, and in the automotive industry. Driving a low-carbon vehicle or the driving style of the driver, inflation of tires, and traffic intensity is some of the factors that may affect the carbon emissions.

The current routing of the company is formed of three round trips. As a first solution, instead of the current trips, if a triangular routing plan is adapted, it is thought that this will mostly cut the emissions and will be beneficial since it annihilates the empty truck movement between nodes of transportation. The second solution approach will only be useful if the company has several locations to visit in a specific area and in the cases where the accessibility of trucks to some areas is harder. This solution includes using one larger truck to transport all products in one site, then parceling out specific deliveries to their local carriers. Another solution can be related to both route-based problems and truck-based problems since it answers the question of which fleet type to use, and it includes a physical change in the current fleet. An 
alternative solution can be using a new and modern fleet instead of their current one or changing the type of transportation. In some cities, there are suggestions on using hydrogen power or solar energy vehicles and electric vehicles or dual-energy vehicles instead of the current ones in traffic [1]. However, a significant change in the vehicle types may not be sufficient for a problem where the transportation includes large volumes of fast-moving consumer goods between long distances, since it may require a large budget for the investment.

Decisions including the height, weight or the fullness of each truck, inner temperature of trucks, aerodynamics of trucks, tire inflations, full or incomplete combustion of fuel in the combustion chamber, and efficient usage of the fleet can be listed as the subcategories of the truck-based problems. Since truck-based problems respond to the decisions about the load volumes and weights, using fully loaded trucks or heavier loads in transportation from each node to another will result in a more efficient and sustainable transportation system.

It is also known that the harder the truck moves forward, the more the fuel it uses. This hypothesis is also related to the friction between the road and the tires; therefore, the system can also be utilized by alternative improvement techniques on physical properties of the vehicles in the fleet. Thus, it is important for a vehicle to have a suitable aerodynamic design in a coordinated manner with the physical design of the vehicle, which may include the type of tires or the inflation of tires in some cases, and this can be achieved implementing different strategies for physical and mechanical truck-based problems. By deciding on the correct tire pressure and tire type addition to the design changes in the overall truck, it may be possible to obtain a $5-11 \%$ of fuel reduction and $9 \%$ carbon dioxide emission reduction in total.

Another main cause of the emission is the speed and traffic-based problems, which include decisions on which hours of the day should the trucks travel at which speed, acceleration of vehicles, and in some cases, this root cause should also cover the road infrastructures under its umbrella. The optimum speed, acceleration of the vehicle, and traffic hours during the whole travel are mentioned as an important controlling factor for emissions. Thus, an implementation on controlling the speed and trafficbased problems will be $5-10 \%$ effective in means of its fuel savings, and it will provide a $7 \%$ decrease in the carbon footprint.

Finally, fuel-based problems consist of decisions on different types of alternative fuels and the legal requirements that they need to satisfy in each country. On the other hand, the fuel-based problems are not only limited to the scope of transportation of different companies. All around the world, there are ongoing debates about the usage of alternative energy sources instead of fossil fuels, since there is no shortage of them in the near future. However, because of the least cost of fossil fuels, they are commonly preferred among others, but this time, it will lead to an increase in the carbon emissions. Examples for alternative types of fuels are given as biofuels, liquefied natural gas (LNG), compressed natural gas (CNG), gas-to-liquids (GTL), hydrogen fuel cells, and electric vehicles [2].

Since there are many companies from different areas which try to decrease their carbon footprint by various approaches, the efficiency of the outcomes of their solution techniques differs. A summary of the alternative solution techniques for the 
Table 1 Estimated reduction in fuel and carbon emissions for alternative solutions

\begin{tabular}{l|l|l|l}
\hline $\begin{array}{l}\text { Solution } \\
\text { methodology }\end{array}$ & $\begin{array}{l}\text { Estimated fuel } \\
\text { reduction }\end{array}$ & $\begin{array}{l}\text { Estimated } \mathrm{CO}_{2} \\
\text { reduction }(\%)\end{array}$ & Source \\
\hline $\begin{array}{l}\text { Improvement in } \\
\text { aerodynamics of } \\
\text { trucks }\end{array}$ & $3-15 \%$ & 6 & $\begin{array}{l}\text { Carbon war room } \\
\text { research report }\end{array}$ \\
\hline $\begin{array}{l}\text { Improvements in tire } \\
\text { pressure }\end{array}$ & $5-11 \%$ & 9 & $\begin{array}{l}\text { Ramachandran et al. } \\
{[3]}\end{array}$ \\
\hline $\begin{array}{l}\text { Speed and } \\
\text { acceleration } \\
\text { optimization }\end{array}$ & $5-10 \%$ & 7 & $\begin{array}{l}\text { Ramachandran et al. } \\
{[3]}\end{array}$ \\
\hline Route optimization & Not mentioned & $\sim 60$ & Tice [4] \\
\hline $\begin{array}{l}\text { Change in fleet } \\
\text { (design and fuel) }\end{array}$ & Not mentioned & 20 & Tice [4] \\
\hline $\begin{array}{l}\text { Alternative fuel } \\
\text { usage (CNG) }\end{array}$ & Not mentioned & 16.2 & Beuthe et al. [2] \\
\hline
\end{tabular}

root causes of the carbon dioxide emissions is given as follows. As the majority of those approaches include route optimization and change in the fleet as an effective solution methodology, it is reasonable to focus on route-based problems and truckbased problems and try to suggest alternative and feasible solutions in that area. In the further steps of this study, the main approach will be concentrating on the two root factors which will likely result in more significant improvements in the carbon dioxide emission levels of the company (Table 1).

\subsection{Company X}

The company maintains its manufacturing operations in every continent except Antarctica, and its products are sold in 190 countries. Two billion consumers use its products on a daily basis, and seven out of ten households around the world have Company X's products. According to Statista (2016), the company was ranked among the top 10 largest fast-moving consumer goods (FMCG) companies in the world with net sales of about 59.19 billion U.S. dollars based on generated net sales. The company has more than four hundred brands, but it mainly focuses on thirteen brands with more than $€ 1$ billion sales a year. Its products can be categorized into four groups: personal care goods, foods, refreshment goods, and homecare goods. The turnover values for those categories are: 20.1, 12.9, 10.1, and 10.2 billion Euro, respectively, according to annual report and accounts 2015 report of the company.

They exist in Turkey market for more than hundred years, and today, one million customers in Turkey use brands of them. Company X not only meets customer demand in Turkey, but also contributes to Turkey's economy by employing Turkish workers, farmers, and suppliers. For manufacturing operations, Company X makes 
a lot of investments yearly in eight factories and sales activities in Turkey with more than five thousand employees. Ninety-five percent of the products of Company X are produced in Turkey and being exported to thirty-four countries. Therefore, Turkey is one of the most important centers of logistics, brand-product development, finance, and research and development for the company.

The factories of the company in Turkey are located according to categories of the products. Ice cream factories are located in City A and City B. Margarine factory is in City A, and a tea packing and sauce and soup/bouillon factory is in City C. The factory of detergent, home, and personal care product is in City D. There are three tea factories in City E. In addition, a factory of house cleaning and personal care products which is still under construction is located in City B. The company has six warehouses for its logistic operations which are categorized into three groups according to the storage temperature of warehouses. Frozen warehouses are located in City A and City B. The chilled warehouse is in City A. The ambient warehouses are located in City D, City B, and City E; however, City D warehouse will not continue to operate after March 2017.

\subsection{System Description}

The company manages a very large volume of production every day and communicates a big portfolio of customers while transporting its goods. Consideration of the transportation volume urges the company to take environmental precautions in order to diminish its impact on the world and be the pioneer in this issue. One of the main goals of the company is to transform its operations into an environmentally sustainable manner. For to that strategy, in 2010, the company launched a plan and shaped its vision through this plan. The plan helps to decrease the environmental footprint of the company and increase positive social impact.

This study focuses specifically on reducing the carbon emission generated due to the company's transportation system in Turkey. The company wants to develop a strategy on transportation rather than other components of the emission because control capability of the company is limited in other fields. To be more specific, raw materials, manufacturing processes, and retailing require bilateral actions, and hence, they include a third-party action in those processes. On the other hand, the transportation system of the company is kept highly private by opening tenders annually and having transport companies only working for Company X. In addition, transportation is a better area to work on rather than disposal steps because disposal requires tracking of goods after the sale, and it is less efficient in the return on investment when compared to transportation. According to the plan, the company aims to decrease the gas emission by reducing it 5\% each year and end up with $40 \%$ emission reduction by 2020 . For this purpose, a key performance measure $\left(\mathrm{KPI}_{2}\right)$ is selected by the firm and given in order to be able to compare the findings and recommended solutions for the problem. 


$$
\mathrm{KPI}_{2}=\frac{\text { Total } \mathrm{kgs} \text { of } \mathrm{CO}_{2}}{\text { ton product }}=\left(\frac{\text { Kilograms of } \mathrm{CO}_{2} \text { from transportation and warehousing }}{\text { Sales volume (tones) }}\right)
$$

According to the data provided by the company, yearly emission levels in terms of $\mathrm{KPI}_{2}$ fail to meet the global goal set in 2015 and in 2016. In 2016, the company opened its new warehouse in City B, and since the shipments are sent from City B instead of City D, this caused an increase in the total traveled distance. This is the main reason behind the unmet aim of minimizing carbon emissions. Carbon dioxide emission levels are shown in Fig. 1, starting from 2011 to 2016 in terms of $\mathrm{kg} \mathrm{CO}_{2}$ per tones moved. Although emission level has increased in 2012 when compared to 2011 , there is a decreasing trend after 2012 till 2016. Emission decrease was $8.6 \%$ from 2011 to 2012, 6.4\% for 2013 when compared to 2012, and for 2014, $7.9 \%$ decrease was obtained. However, $5 \%$ reduction could not be achieved in 2015. After the $2.6 \%$ decrease in 2015 , emission level was increased in 2016 due to pre-specified warehouse location change.

Company $\mathrm{X}$ decides which truck type to use in planning step for its shipments. The first category of the trucks that the company uses is market trucks. It is the cheapest way among all others for full truckloads; however, there is a high risk of burglary. The second category of trucks is fleet trucks. For this category, the cost for returning of trucks is paid as well, and thus, it's a more expensive option than the market trucks. In this option, backhaul utilization is also possible for fleet trucks. Therefore, although the prices are higher, fleet trucks can be preferred among the other options. The price is determined for this truck type as a function of distance and duration of shipment. In addition, additional distances cause extra waiting, and drivers are paid for the waiting times as well. Partial trucks (LTL) have a unit-based payment system. Units can be pallets or cases of goods. When the required amount to be shipped is not much in quantity, it is not the optimal decision for the company to send a market or fleet truck for those goods. In such cases, the firm prefers to use partial trucks. The price of partial trucks is higher when compared to per unit pallet cost in other truck options. However, since the amount to be sent is not much, partial trucks compensate the cost.

Fig. 1 Yearly carbon emission values of the company transportation network ( $\mathrm{kg} \mathrm{CO}_{2} /$ tones sold)

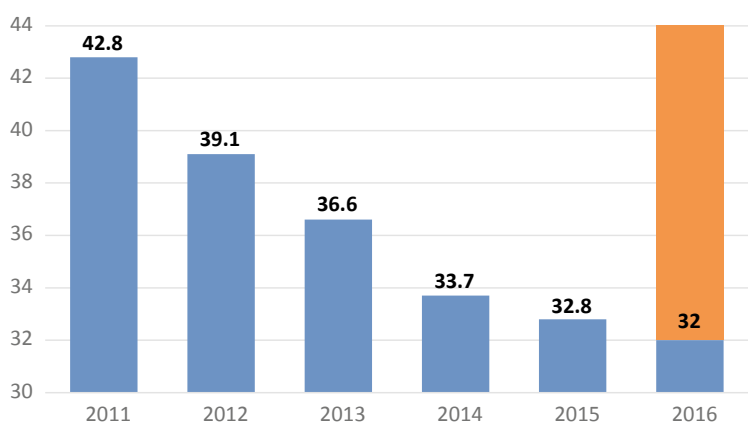


$\mathrm{CO}_{2}$ emission levels for different size of trucks have been investigated to see the effect of truck size, by using a $\mathrm{CO}_{2}$ calculator which is designed to calculate $\mathrm{CO}_{2}$ emission of each particular shipment within company's transportation network. $\mathrm{CO}_{2}$ emission amounts per ton sold for ambient product shipments with different truck sizes and different loadfill values have been calculated and shown in Table 2. Carbon emission level per tones product sold is higher in smaller trucks than bigger trucks. Therefore, total distance traveled by larger trucks should be increased when compared to smaller trucks.

Since the total $\mathrm{CO}_{2} \mathrm{~kg} /$ tones sold decreases when the loadfill of the trucks increase, the shipments originated from different warehouses of Company X Turkey are investigated to examine the current situation. Findings for pallet loadfill of trucks for more than ten thousand shipments made from January 2016 to November 2016 are shown in Table 3.

Since the amount of order given by one customer in a time period is not always sufficient to constitute the whole loadfill of a truck, the route of a truck may consist of multiple customers in multiple cities in some cases. As the number of cities shipped per truck increases, the distance traveled by a truck increases, and this leads to an increase in $\mathrm{CO}_{2}$ emission. While determining the route of trucks which serve to more than one city, Company X Turkey uses nearest neighborhood method. Thus, an individual truck serves firstly to the closest city to the warehouse which the truck is originated from. Lastly, the truck serves to the farthest city to the warehouse and returns to the warehouse without any loadfill on it. If the pallet loadfill in the final city is below a threshold, it means that the distance traveled by that truck with low pallet loadfill is likely to be high, which is an undesired situation for the firm. The

Table $2 \mathrm{CO}_{2}$ emission values of ambient product shipments for different truck sizes and different loadfill

\begin{tabular}{l|c|c|c}
\hline \multirow{2}{*}{ Per shipment $\left(\mathrm{kg} \mathrm{CO}_{2}\right.$ /tones) moved } & Pallet loadfill & \multicolumn{2}{l}{} \\
\cline { 2 - 4 } & $100 \%$ & $75 \%$ & $50 \%$ \\
\hline Tir (24 tones) & 3.87 & 4.84 & 6.77 \\
\hline Tiryon (14 tones) & 5.71 & 7.21 & 10.15 \\
\hline Tiryon (12 tones) & 6.48 & 8.19 & 11.61 \\
\hline Kamyonet (3.5 tones) & 15.61 & 19.44 & 27.10 \\
\hline
\end{tabular}

Table 3 Pallet loadfill of the trucks originated from different warehouses

\begin{tabular}{l|l|l|l}
\hline \multirow{2}{*}{ Product type } & \multicolumn{2}{|l}{} \\
\cline { 2 - 4 } & Pallet loadfill & \multicolumn{2}{l}{} \\
\hline Chilled & $0.6 \%$ & $50-75 \%$ & $>75 \%$ \\
\hline Ambient & $2.2 \%$ & $10.7 \%$ & $88.7 \%$ \\
\hline Frozen & $0 \%$ & $9.7 \%$ & $88.1 \%$ \\
\hline
\end{tabular}


pallet loadfill values, when truck, which serves to more than one city, arrived at the final city are shown in Figs. 2 and 3.

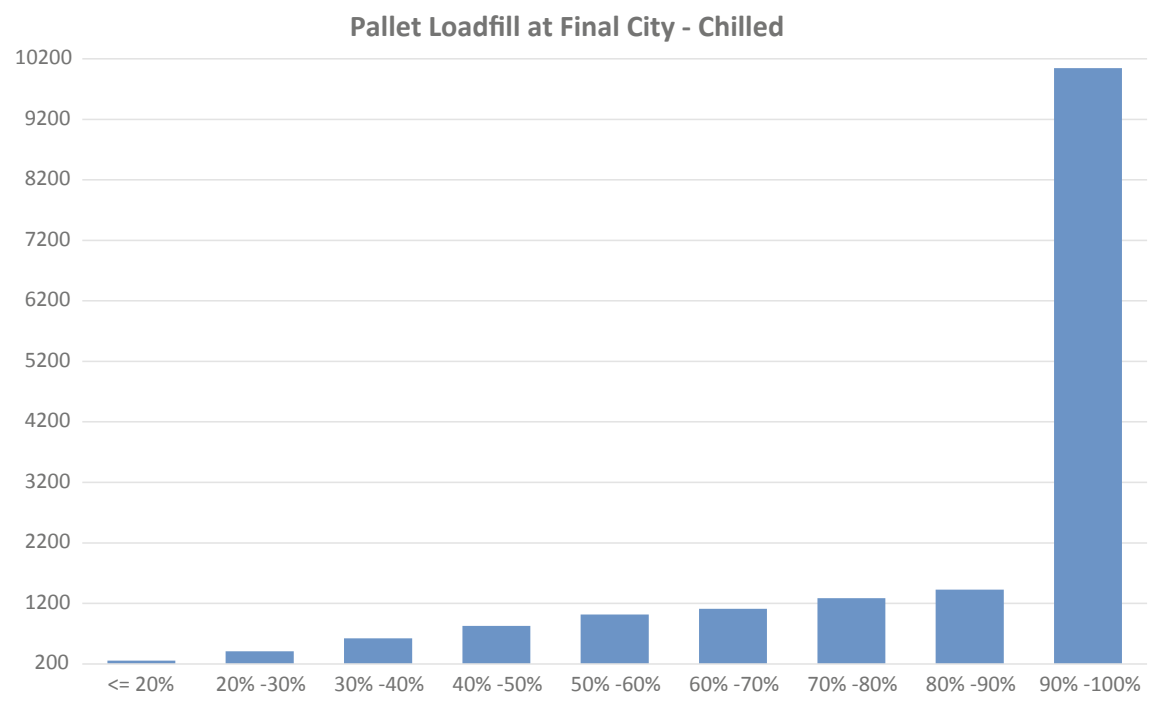

Fig. 2 Pallet loadfill when arrived at final city for trucks which serve to more than one customer and originated from City A chilled warehouse (for shipments made from January 2016 to November 2016)

Fig. 3 Pallet loadfill when arrived at final city for trucks which serve to more than one customer and originated from ambient warehouse (for shipments made from January 2016 to November 2016) 
Table 4 Findings about network efficiency of different product types

\begin{tabular}{l|l|l|l}
\hline Product type & City/shipment & Customer/shipment & Pallet loadfill at final city (\%) \\
\hline Chilled & $1.2-2$ & $3.5-4$ & 92 \\
\hline Ambient & $1.2-2$ & $2.4-3$ & 90 \\
\hline Frozen & $1.6-2$ & $1.9-2$ & 92 \\
\hline
\end{tabular}

With a better transportation planning strategy, the average pallet loadfill when arrived at the final city can increase. The findings about the relevant performance measure tools are shown in Table 4.

The company uses X-Docks in some locations as small warehouses. Products are first shipped to X-Docks with large trucks, and they are transported with smaller trucks from X-Docks to customers. By this way, unnecessary movements of the goods from a customer to another customer can be avoided. Because of this, most efficient usage of X-Docks is aimed. Efficient use of trucks in terms of vehicle loadfill, improved networks, and effective use of advanced technological tools is expected to help to design a transportation system achieving 5\% decrease in carbon dioxide emissions on a yearly basis. Addition to this, it is expected that the outcomes of the study are applicable, cost-effective, and feasible.

\section{Materials and Method}

As mentioned before, there are several root causes for the carbon emissions in logistics, and for these causes, it is possible to suggest alternative solution strategies. This study includes all branches of the diagram and suggests at least one solution method for all of the main reasons for $\mathrm{CO}_{2}$ emissions in the fishbone diagram. Therefore, to reduce the number of proposed solutions and to gather them under a general heading, proposed system is divided into two groups as route-based proposed system and fleet-based recommendations portfolio.

\subsection{Route-Based Proposed System}

Since the carbon emission generated due to big trucks is estimated to be lower than those of smaller trucks when conditions are similar, a model is proposed which aims to maximize total traveled distance with big trucks, while the use of smaller trucks is minimized. New X-Dock locations and a vehicle routing model are proposed in which the predetermined number of trucks is transformed into CNG trucks. The aim is to create the new routing schedule for the transportation system based on the existing CNG station locations and CNG trucks whose number is determined by the firm. By doing so, the model will propose a set of customers who can be served via 
CNG trucks and set of customers who will be served via existing diesel trucks. For this model, different runs will be obtained by changing the number of CNG trucks available to show the difference in the customer set that can be covered so that the firm can decide on the number of vehicles to be transformed into CNG. Methodologies are proposed in line with the product types which can be applied.

\section{Chilled X-Dock Model}

Strategic, tactical, and operational problems are generally known as distribution network design problems (DNDP). There is an interdependence between the location of facilities, number of facilities, and the routing from those facilities to multiple demand points. Because of this interdependence, a need for the combination of $\mathrm{p}$ hub median problems and vehicle routing problems arose. Location-routing problem (LRP) is a special problem under DNDP. It combines facility location problem and vehicle routing problem. Therefore, in a single problem, it is possible to take strategic location and tactical or operational routing decisions simultaneously. In general, LRP is NP-hard and therefore, common approach in solving LRPs is to develop and use a heuristic approach to reduce the complexity in the model.

There are several inputs required for those models to be clearly identified, and some of those inputs are the same for both models, but some of them differ because of the vehicle-based differences between two types of goods. Since the real-life implementation of this includes cases where some of the customers cannot accept all types of trucks, the vehicle to customer assignments should also consider this constraint within the model. The aim of the proposed model is to minimize carbon emissions without giving up on any customer demand in a timely manner. Therefore, all inputs for the model are determined relatively with this aim in order to determine the outputs of the model, which are: X-Dock locations, the macro-scale transportation of products from warehouses to X-Dock locations, and the micro-scale transportation of products from X-Dock locations to customers with smaller trucks.

In order to offer a X-Dock model for chilled goods, LRP is developed to select the optimum X-Dock locations among 81 possible candidate cities. Then, the model routes vehicles between these X-Dock locations and cities in order to serve the customer portfolio of the company. There are three vehicle types in terms of their sizes. They are classified into two categories as big-sized trucks and smaller-sized trucks. In this case, the model should also consider the emissions from the cooler fuel, in addition to the engine fuel, since those vehicles should be transported in an at most $4{ }^{\circ} \mathrm{C}$ environment.

There are six sets within the model as $C=\{1, \ldots, n\}, S=\{n+1, \ldots, n+S\}$, $V=\{1, \ldots, n+S+1\}$, and $K=\{1, \ldots, b+s\}$ where $b$ is the number of big-sized vehicles and $s$ is the number of small-sized vehicles in the fleet, $B V=\{1, \ldots, b\}$ and $S V=\{1, \ldots, s\}$; which represent customers, X-Docks, all sites, all vehicles, big vehicles, and small vehicles, respectively. $N+S+1$ shows the depot. $a 1_{k}$ and $a 2_{k}$ are the fuel consumption of empty small and big vehicles, respectively, where $b 1_{k}$ and $b 2_{k}$ represent the fuel consumption of small- and big-sized vehicles per ton 
load and $\mathrm{km}$. Additionally, for vehicles that transport frozen goods, $c 1_{k}$ and $c 2_{k}$ are cooler fuel consumption parameters for small and big vehicles. CAP $1_{k}$ and CAP $2_{k}$ are load capacities for vehicles, DIST $_{i j}$ is the distance between vertex $i$ and $j$, and finally, DIST $2_{s}$ is used to define the distance between depot and a total number $r$ of X-Docks. $X_{i j k}$ is one if vehicle visits $j$ right after visiting $i, f_{i j k}$ shows the flow between $i$ and $j$ with vehicle $k, W_{s}$ becomes one when a X-Dock is open, $Y_{s k}$ is one if a big vehicle is assigned to one of opened X-Docks, and finally, $u_{i k}$ is the order of visit to $i$ with vehicle $k$.

$$
\begin{aligned}
& \operatorname{Min} \sum_{\substack{i, j \in V \\
i \neq j}} \sum_{\substack{k \in S V \\
i \neq j}}\left\{\left[\left(a_{k} \times X_{i j k} \times \operatorname{DIST}_{i j}\right)+\left(b_{k} \times f_{i j k} \times \mathrm{DIST}_{i j}\right)\right.\right. \\
& \left.+\left(c_{k} \times X_{i j k} \times \frac{\mathrm{DIST}_{i j}}{\mathrm{vel}}\right)\right]+\sum_{j \in S, k \in B V}\left[\left(a 2_{k} \times Y_{j k} \times \mathrm{DIST}_{s}\right)\right. \\
& \left.\left.+\left(b 2_{k} \times \text { flow }_{j k} \times \mathrm{DIST} 2_{s}\right)+\left(c 2_{k} \times Y_{j k} \times \frac{\mathrm{DIST} 2_{s}}{\mathrm{vel}}\right)\right]\right\} \text { s.to } \\
& \sum_{j \in S} Y_{j k} \leq 1 \quad \forall k \in B V \\
& \sum_{i \in S, j \in V} X_{i j k} \leq 1, \quad \forall k \in S V \\
& X_{i j k}=0, \quad \forall i, j \in S, k \in S V \\
& \sum_{i \in V, k \in S V} X_{i j k}=1, \quad \forall j \in C \\
& \sum_{j \in S, k \in S V} V_{i j k}=1, \quad \forall i \in C \\
& \begin{array}{ll}
\sum_{i \in V} X_{i j k}= & \sum_{i \in V} X_{j i k} \forall j \in C, k \in S V \\
i \neq j & i \neq j
\end{array} \\
& \sum_{j \in C} X_{i j k}=\sum_{j \in C} X_{j i k} \quad \forall i \in S, k \in S V
\end{aligned}
$$




$$
\begin{gathered}
f_{i j k} \leq \mathrm{CAP}_{k} \times X_{i j k}, \quad \forall i, j \in V, k \in S V \\
\sum_{j \in V} f_{s j k}-\sum_{i \in C} \mathrm{DEM}_{i} \times V_{i s k}=0, \quad \forall s \in S, k \in S V \\
u_{i k}-u_{j k}+N \times X_{i j k} \leq N-1, \quad \forall i \in V, j \in C, k \in S V \\
u_{i k} \leq N-1, \quad \forall i \in C, k \in S V \\
\sum_{s \in S} W_{s}=r \\
X_{s j k} \leq W_{s} \quad \forall s \in S, j \in C, k \in S V \\
V_{j s k} \leq W_{s} \quad \forall s \in S, j \in C, k \in S V \\
X_{i j k} \in\{0,1\} \quad \forall i, j \in V, \forall k \in S V \\
f_{i j k} \geq 0 \quad \forall i, j \in V, \forall k \in S V \\
V_{i j k} \in\{0,1\} \quad \forall i \in C, j \in S, \forall k \in S V \\
u_{i k} \geq 0 \quad \forall i \in V, \forall k \in S V \\
W_{s} \in\{0,1\} \quad \forall s \in S
\end{gathered}
$$

The objective function for both of the chilled X-Dock model and the ambient XDock model minimizes the total carbon emissions due to the transportation of goods. The remaining constraints of the two models are the same. Constraint (2) allows each truck to visit at most one cross dock. Constraint (3) implies that each small vehicle must be assigned to at most one route starting from one of the open crossdock locations. Constraint (4) prevents small vehicles to travel between cross docks. Constraints (5) and (6) allow each small vehicle to serve only one customer and each customer to be assigned to only one cross-dock location simultaneously. Constraint (7) and Constraint (8) are the flow balance constraint for small vehicles that leave customers and cross docks, respectively. According to the Constraint (9), the model blocks the possibility of transferring goods which excesses the capacity of trucks and determines the upper bound of flow. Constraints (10) makes sure that each truck leaving the cross dock is loaded with the total demand of customers that will be served with that specific truck. Constraints (11) and (12) are the Miller-Tucker-Zemlin 
(MTZ) constraints. Constraint (13) is the constraint that determines the number of cross docks to be opened. Constraint (14) and Constraint (15) ensure that vehicles and customers can only be assigned to the same cross dock if that cross dock is opened.

\section{Chilled CNG Model}

In this study, the aim is to consider the routing and refueling station locating problems simultaneously. By this, it will result in a true optimal rather than a local optimal solution. At this phase of the study, node-based vehicle routing problem (N-BVRP) is developed for $\mathrm{CNG}$ implementation in vehicles used in the transportation of chilled and frozen goods. There is one main warehouse location for chilled goods, and it is located in City A. Warehouse is denoted as node 0 in the model. Within the scope of the model, based on the company's demand, it is assumed that CNG model can only be adapted to a single type of vehicle which is $22 \mathrm{~T} 33 \mathrm{P}$ articulated trucks. There are three underlying assumptions as follows: There is exactly one visit to each customer every day, a customer set is defined in the model including only the customers who have demand for that day and the values in this set change according to the daily demands, and finally, each depot is assumed to be a station. It is possible for a vehicle to visit multiple CNG stations in one route if it cannot reach any point without any refuel. In the model, all locations are given based on city locations, and to prevent the model to block any revisit to a specific station, dummy CNG stations are defined and added to the set of stations by duplicating the original stations.

This time, set definitions are changed as $V=\{1, \ldots, n+2 S\}$ is the set for all sites, and $K=\{1, \ldots, M\}$ is the set of all vehicles. The customer set is kept the same, and however this time, a new set of CNG stations $S=\{n+1, \ldots, n+2 S\}$ is introduced. This time the model and parameters are simplified as follows: fuel consumption of empty vehicle $a$, fuel consumption of vehicle per ton load and $\mathrm{km}$ $b$, and cooler fuel consumption of vehicle is $c$. The number of CNG vehicles in the fleet is $M$, and the capacities of those vehicles in tones are $\mathrm{CAP}_{k}$ where the fuel tank capacity if shown with $Q$. For the additional decision variables, $R_{j k}$ is the remaining fuel level of vehicle $k$ after delivered to $j$.

$$
\begin{gathered}
\operatorname{Min} \sum_{\substack{i, j \in V, k \in K \\
i \neq j}}\left\{\left[\left(a_{k} \times X_{i j k} \times d_{i j}\right)+\left(b_{k} \times f_{i j k} \times d_{i j}\right)\right.\right. \\
\left.\left.+\left(c_{k} \times X_{i j k} \times \frac{d_{i j}}{\text { vel }}\right)\right\}\right] \text { s.to } \\
\sum_{\substack{j \in V \\
j \neq i}} X_{0 j k}=\sum_{j \in V} X_{j 0 k} \quad \forall k \in K
\end{gathered}
$$




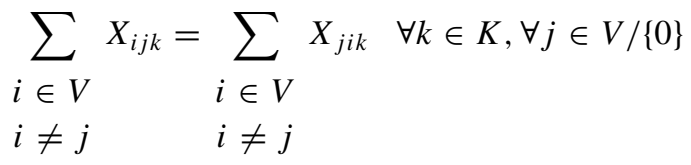

$$
\begin{aligned}
& \sum_{i \in V} \sum_{k \in K} X_{i j k}=1 \quad \forall j \in C \\
& \sum_{i \in V} \sum_{j \in S} X_{i j k} \leq 1 \quad \forall k \in K \\
& j \neq i \\
& \sum_{j \in V /\{0\}} X_{0 j k} \leq 1 \quad \forall k \in K \\
& f_{i j k} \leq \mathrm{CAP}_{k} \times X_{i j k} \quad \forall k \in K, \forall j \in V, \forall i \in V \\
& R_{i k}-\left(a \times \operatorname{DIST}_{i j} \times X_{i j k}\right)-\left(b \times \operatorname{DIST}_{i j} \times f_{i j k}\right)-\left(c \times \frac{\mathrm{DIST}_{i j}}{\operatorname{vel}} \times X_{i j k}\right) \\
& +Q \times\left(1-X_{i j k}\right) \geq R_{j k} \quad \forall k \in K, \forall i \in C, \forall j \in V, j \neq i \\
& Q-\left(a \times \operatorname{DIST}_{i j} \times X_{i j k}\right)-\left(b \times \mathrm{DIST}_{i j} \times f_{i j k}\right)-\left(c \times \frac{\mathrm{DIST}_{i j}}{\operatorname{vel}} \times X_{i j k}\right) \\
& +Q \times\left(1-X_{i j k}\right) \geq R_{j k} \quad \forall k \in K, \forall i \in C, \forall j \in V \\
& \sum_{i \in V} f_{0 i k}-\sum_{i \in V} \sum \operatorname{DEM}_{i} \times X_{i j k}=0 \quad \forall k \in K \\
& j \in V, i \neq j \\
& u_{i k}-u_{j k}+N \times X_{i j k} \leq N-1 \quad \forall k \in K, \forall i \in V, \forall j \in V /\{0\}, j \neq i \\
& u_{i k} \leq N-1 \quad \forall k \in K, \forall i \in V /\{0\} \\
& X_{i j k} \in\{0,1\} \quad \forall i, j \in V, \forall k \in K \\
& f_{i j k} \geq 0 \quad \forall i, j \in V, \forall k \in K
\end{aligned}
$$

The objective function for both of the chilled CNG model and the frozen CNG model minimizes the total carbon emissions due to the transportation of goods. The remaining constraints of the two models are the same. Constraint (23) makes sure that each customer is served with only one truck. Constraint (24) implies that each station can be visited at most once during a tour. Constraint (25) allows each vehicle to be assigned to at most one route. According to the Constraint (26), the model blocks the 
possibility of transferring goods which excesses the capacity of trucks and determines the upper bound of flow. Constraints (27) and (28) are the fuel restriction constraints that limit the movement of vehicles between vertices if there is no sufficient amount of fuel left in each vehicle. Constraint (29) makes sure that each truck leaving the depot is loaded with the total demand of customers that will be served with that specific truck.

\section{Ambient X-Dock Model}

For X-Dock offering model in ambient goods, the same strategy with chilled products is applied. For ambient products, the company owns four types of vehicles which are 24T 32P market trucks, 14T 20P fleet trucks, 3T 6P market trucks, and partial trucks. Since the company is not the owner of all goods in partial trucks, those types of vehicles are ignored in the model. Differences between two models are the change in the number of vehicle types and the change in the objective function. The difference in the objective function for the chilled X-Dock model represents the additional carbon dioxide emissions due to the use of cooler fuel in chilled trucks. The remaining constraints of the two models are the same.

\section{Frozen CNG Model}

For CNG model in frozen goods, the same strategy is used with chilled goods. Chilled and frozen goods' CNG models differ from each other in means of the number of warehouse locations. While there is one warehouse for chilled goods, there are three warehouses in City F, City A, and City B, where chilled goods are located.

\subsection{Fleet-Based Recommendations Portfolio}

Improvements in the aerodynamics of trucks can provide a high reduction in $\mathrm{CO}_{2}$ emission. Additional retrofit technologies include aerodynamic fairings which are attached to different parts of trucks' cabin and trailers. Those fairings can be attached to a truck singly or as a combination. Improvements in the aerodynamics of truck can be achieved in two ways. The first option is replacing the existing fleet with new truck models which have more aerodynamic design and popular in transportation. The second option is improving the aerodynamics of existing fleet through additional retrofit technologies. Since replacing existing trucks with new trucks requires high investment, the second option is considered in this study.

Company Turkey uses different truck types and categories in its transportation network. There is not any standardization about the aerodynamic properties of the truck. Some of the trucks have already aerodynamic fairings attached to their trucks' cabin, while some of them do not have. The procurement department has informed that they are capable of buying the fairings around 720 Turkish Liras for one truck. Due to time restrictions, return of investment analysis was based on to $3 \%$ fuel reduction in frozen fleet of The Company Turkey. After some estimations in yearly kilometers and the demand stability for that fleet, the analysis has conducted that 
the investment can be compensated in 1.85 month after the implementation of the strategy with yearly $96,000 \mathrm{~L}$ fuel saving.

According to the findings, it is seen that speed and acceleration play a significant role in carbon emissions. Speed and acceleration optimization reduces fuel consumption by $5-10 \%$ while decreasing the level of $\mathrm{CO}_{2}$ emissions by $7 \%$. Therefore, optimal speed values will be recommended to achieve lowest fuel consumption and carbon emission levels. Researches indicate that acceleration requires a large input of energy, and therefore for fuel economy and lower carbon emissions, steady speed is crucial since the rate of carbon emission is the lowest at a steady speed [5]. Based on the literature review and speed limitation given by General Directorate of Highways of Turkey, optimal speed ranges are recommended while taking vehicle size and road type into account.

Since tire inflation has a role in $\mathrm{CO}_{2}$ emissions, it is important to concentrate on it to determine the optimal tire pressure for different types of trucks in different product types. Company Turkey uses market trucks for the shipment of ambient goods, therefore, study on determining tire inflation is performed on only chilled and frozen good. For the shipment of frozen goods, the company uses only one type of truck. However, there are 11 different contractors responsible for the shipment of chilled goods, and since properties of those trucks differ from each other, different tire pressure values are suggested relatively. Tables 5 and 6 show the technical properties of chilled and frozen trucks, respectively.

Maintenance of optimal conditions has a significant role in the sustainability of this application. In addition, regular control of tires and tire pressure at least once in a month will be useful to determine any changes in those values.

Table 5 Technical properties of chilled trucks and suggested tire pressure

\begin{tabular}{l|l|l|l|l|l|l}
\hline Contractor & \# of tires & Tire size & \# of axle & $\begin{array}{l}\text { Empty load } \\
\text { on axles } \\
(\mathrm{kg})\end{array}$ & $\begin{array}{l}\text { Load on } \\
\text { axles (kg) }\end{array}$ & $\begin{array}{l}\text { Suggested } \\
\text { tire } \\
\text { pressure } \\
\text { (bar) }\end{array}$ \\
\hline Kutlu Tir & 12 & $12.5 \mathrm{R} 22.5$ & 5 & 12,500 & 25,000 & 5.5 \\
\hline $\begin{array}{l}\text { Kutlu Tir } \\
\text { (Crone) }\end{array}$ & 12 & $\begin{array}{l}295 / 80 \mathrm{R} \\
22.5\end{array}$ & 5 & 17,850 & 40,000 & 9 \\
\hline Gül Tiryon & 10 & $12.5 \mathrm{R} 22.5$ & 3 & 11,700 & 13,300 & 5.5 \\
\hline Gül Tiryon & 10 & $12.5 \mathrm{R} 22.5$ & 3 & 11,800 & 13,200 & 5.5 \\
\hline Gül Tiryon & 10 & $12.5 \mathrm{R} 22.5$ & 3 & 12,300 & 12,700 & 5.5 \\
\hline $\begin{array}{l}\text { Gül } \\
\text { Kamyonet }\end{array}$ & 6 & $\begin{array}{l}215 / 75 \mathrm{R} \\
17.5\end{array}$ & 2 & 3750 & 4150 & 4 \\
\hline $\begin{array}{l}\text { Karsan } 12 \\
(25-20\end{array}$ & 10 & $12 \mathrm{R} 22.5$ & 3 & 13,200 & 25,000 & 5.5 \\
\hline $\begin{array}{l}\text { Ford) } \\
\text { Karsan Tir }\end{array}$ & 12 & 3157022.5 & 5 & 17,200 & 40,000 & 9 \\
\hline
\end{tabular}


Table 6 Technical properties of frozen trucks and suggested tire pressure

\begin{tabular}{l|l|l|l|l|l|l}
\hline Contractor & \# of tires & Tire size & \# of axle & $\begin{array}{l}\text { Empty load } \\
\text { on axles } \\
(\mathrm{kg})\end{array}$ & $\begin{array}{l}\text { Load on } \\
\text { axles }(\mathrm{kg})\end{array}$ & $\begin{array}{l}\text { Suggested } \\
\text { tire pressure } \\
\text { (bar) }\end{array}$ \\
\hline Karsan Tir & 12 & 3157022.5 & 5 & 17,200 & 40,000 & 9 \\
\hline
\end{tabular}

\subsection{Implementation Plan}

Within the scope of proposed route-based recommendations, both CNG and X-Docks models are verified and validated by using Xpress optimization software for small instances of the problem up to eight nodes. However, since NP-hard models are combined to form the CNG model and the X-Dock model, it caused some issues while solving for optimality in bigger scenarios. While implementing the models to the transportation system of The Company Turkey, including all of the nodes in its transportation network, Xpress had difficulties finding the optimal solutions. At this stage, some heuristics are constructed in order to solve both of those models under real-life constraints.

For X-Dock model in both ambient and chilled goods, the optimization software was finding the optimal X-Dock locations based on daily customer locations, their demands, and the routes of each truck used from warehouse to selected X-Dock locations and from selected X-Dock locations to daily customers. As the first heuristic approach, problem is divided into two parts, and two separate Xpress models are created. K-hub median problem is utilized to determine the places of X-Docks in the first Xpress model by not considering the routes. In this Xpress model, the places of X-Dock locations are determined after the user inputs the number of X-Docks to be opened. While doing that, the model considers the demand and place of the customers of that day and sums the total demand of customers if they are in the same city. After obtaining the city-based demand amounts, Xpress is connected to an Excel file, which creates a distance matrix consisting only the cities in which the customer demand exists that day and sends it to the Xpress to use. With those information, Xpress reports the X-Dock locations which offer the least $\mathrm{CO}_{2}$ emission. Therefore, the output of this first Xpress model is the X-Dock locations and the assignment of each city existing in that day's demand list to one of the X-Dock locations based on leading the least carbon emission level.

The next step after obtaining the determined places of X-Docks is to serve the customers by starting the supply of goods from the main warehouse to selected XDock locations with big trucks and rotating the smaller trucks from the X-Dock locations to customers in a proper route. A second Xpress model is created, which is performing the rotations of smaller trucks starting from the X-Dock locations to customers when the user enters the data to that model.

The nearest-neighbor heuristic is one of the first heuristics applied to determine a solution to travelling salesmen problem (TSP). To apply nearest-neighbor heuristic $(\mathrm{NNH})$, the salesman starts from a randomly selected city and then visits the nearest 
city after it. Then, it goes to the unvisited city closest to the city that has most recently been visited. A complete tour is obtained by leaving none of the cities unvisited. In both CNG model and X-Dock model, NNH is used as a construction heuristic to come up with an initial tour. The X-Docks locations are selected by inputting the number of $\mathrm{X}$-Dock locations equals to one, three, and five as three different scenarios with the same customer demand input. Following the X-Dock selection, by using the emission calculator that has been created in the beginning of the study, corresponding carbon emissions generated from the routes starting and ending in those X-Dock locations are calculated. After analyzing the outcomes, an intensity map is created showing the optimal location for a X-Dock based on the number of times a city is selected. After determining the number of X-Dock locations and the places that are most effective to submit to the company, the cities in Turkey are assigned to those X-Dock locations so that users from the company will have the opportunity to route the trucks. The intensity maps for three different numbers of X-Dock scenarios are shown in Figs. 4, 5 , and 6 , respectively.

The CNG routing model could not achieve the routing based on available CNG station locations and the daily demand due to increase in the distance matrix since the stations were being entered to matrix multiple times to allow multiple visits for different trucks. Therefore, a similar logic to code NHH is adapted, but differently, it considers the remaining fuel level. By using the available number of trucks and considering their closeness to both depot and to each other, model creates the most logical set of customers to be shipped with the CNG trucks by using the available stations nearby if their remaining fuel is not adequate. The tours start and end in the main warehouse, and the model informs the user if the available number of trucks cannot serve all customers due to lack of CNG trucks to be utilized. Since the company has not completed the procurement of all CNG transformation in their fleet and CNG stations are not distributed as homogenously as diesel stations in Turkey, in order not to increase the total traveled distance, the final deliverable to the company

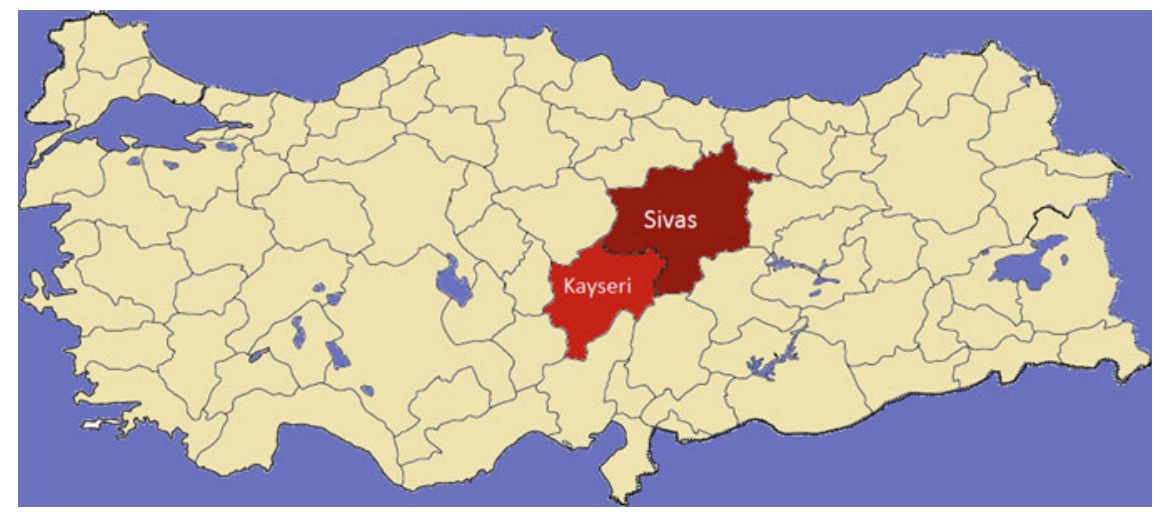

Fig. 4 X-Dock intensity map with one possible X-Dock location 


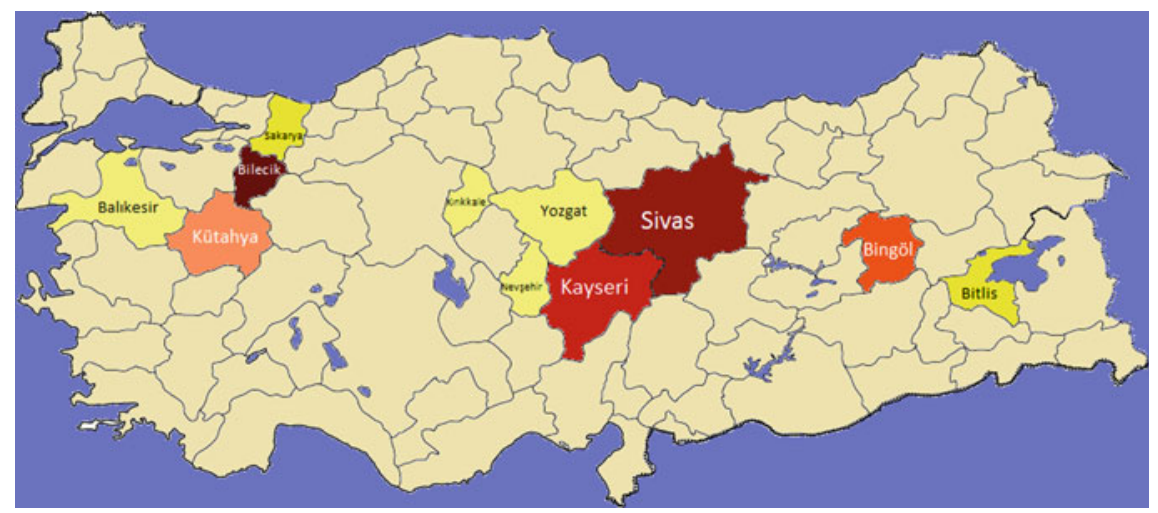

Fig. 5 X-Dock intensity map with three possible X-Dock locations

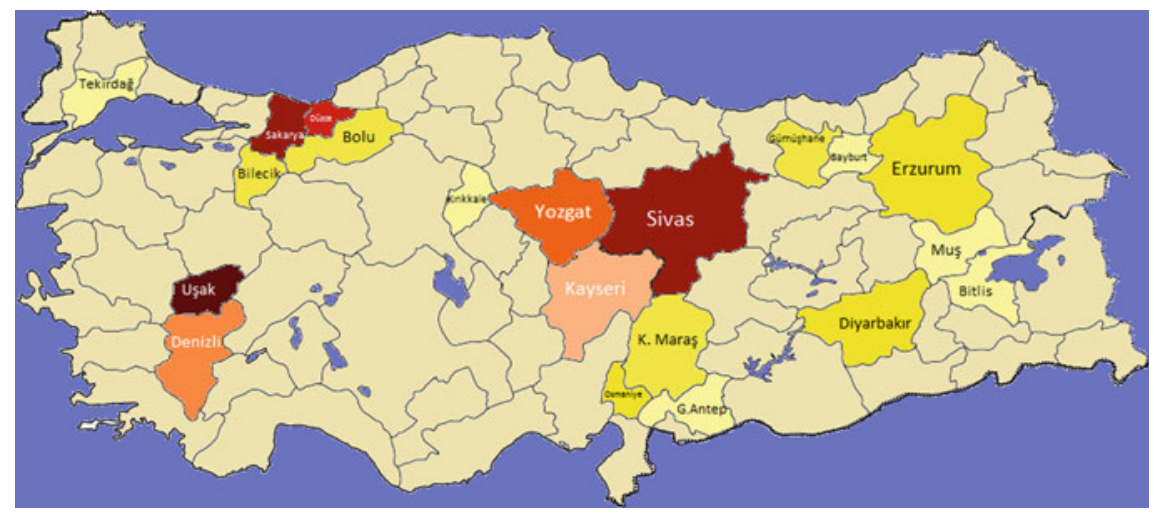

Fig. 6 X-Dock intensity map with five possible X-Dock locations

will be the specific regions and cities to use CNG trucks to supply the daily demands of their customers at the end of the study.

\section{Results and Discussion}

In order to see the improvement compared to the current system and recommend the possible locations of X-Dock to be opened, thirty-day sales data are analyzed with three different numbers of X-Docks scenarios. As a result, from thirty days with one $\mathrm{X}$-Dock location, the average $\mathrm{CO}_{2}$ emission is $13,220.4 \mathrm{~kg}$, with three $\mathrm{X}$ Dock locations average is $8896.86 \mathrm{~kg}$, whereas with five X-Dock locations average is $8116.8 \mathrm{~kg}$ which indicates the most efficient scenario. When those scenarios are compared to the current system of the company, improvements are obtained as 13.08 
and $20.70 \%$ for the three and five X-Dock locations, respectively. However, for the one $\mathrm{X}$-Dock location scenario, the average carbon emission value is higher than the current system, and it can be said that it is not reasonable to open one X-Dock location according to the current system of the company. Intensity maps show the possible locations of X-Docks to be opened from most preferred to least. Most preferred cities are shown with the darkest colors, while least ones are shown with lighter colors. Therefore, it can be said that for the three X-Dock locations, frequently offered cities are Bilecik, Sivas, and Kayseri, and for the five X-Dock locations, most preferred cities are Uşak, Sakarya, Sivas, Düzce, and Yozgat to open X-Dock locations.

\section{Conclusion and Future Work}

It can be seen that $\mathrm{CNG}$ fuel implementation has an important effect on reducing emission levels. Therefore, CNG implementation to some fleet, which uses routes that have easy access to CNG stations, decreases the amount of gas emissions since this scenario enables the driver to serve the customers without increasing the total traveled distance. For future work, considering customers' demand intensity, information could be reasonable to come up with possible locations to establish new CNG stations to benefit from both low cost and low-carbon emission opportunities, instead of settling for the existing stations and creating restricted routes because of the necessities.

\section{References}

1. Li H (2016) Study on green transportation system of international metropolises. Procedia Eng 137:762-771

2. Beuthe M, Gasca J, Greene D, Lee DS, Muromachi Y, Newton PJ, Plotkin S, Sperling D, Wit R, Zhou PJ (2007) In: Bose R, Kheshgi H (eds) Transport and its infrastructure. Climate change report, pp 323-380

3. Ramachandran K, Kanchustambham S, Wingerden V, Ladipo O, Aggarwal S, Rucke A, Rigel A (2012) In: Lee TM, Cullinen MS (eds) Road transport: unlocking fuel-saving technologies in trucking and fleets. Carbon war room research report, pp 1-28

4. Tice C (2013) How to calculate and reduce your business's carbon footprints? Entrepreneur. Accessed at https://www.entrepreneur.com/article/226467 as of 13 Nov 2016

5. Kay D (2013) The impact of $20 \mathrm{mph}$ limits on carbon emissions and air quality. In: 4th annual 20mph conference

6. Wiedmann T, Minx J (2008) A definition of carbon footprint. In: Ecological economics research trends, Chapter 1. Nova Science Publishers, Hauppauage NY, USA, pp 561-596 